Brit. Heart J., 1963, 25, 709.

\title{
PREDNISONE IN THE TREATMENT OF ADAMS-STOKES ATTACKS
}

\author{
BY \\ D. VEREL, S. J. MAZURKIE, AND F. RAHMAN \\ From the Department of Cardiology, United Sheffield Hospitals, and City General Hospital, Sheffield \\ Received January 28, 1963
}

Adams-Stokes attacks are seen most frequently in patients with heart block. They are usually due to a temporary cardiac arrest not infrequently occurring when an incomplete heart block becomes complete, although a number of other irregularities may precipitate unconsciousness in these patients (Parkinson, Papp, and Evans, 1941). They occasionally occur in patients with bradycardia from other causes. The traditional treatment with ephedrine is usually effective in abolishing the syncopal attacks but in some patients episodes of unconsciousness may defy medication and confine the patient to bed. Prinzmetal and Kennamer (1954) reported that corticotrophin was effective in preventing ventricular asystole in posterior cardiac infarction. Since then a variety of corticosteroids have been reported as useful in the treatment of Adams-Stokes attacks, but the régime does not seem to have been generally adopted, possibly because the natural history of Adams-Stokes attacks in heart block is one of remissions which make evaluation of any therapy difficult. A trial of prednisone in Adams-Stokes attacks was undertaken and this paper reports two years' experience of this therapy. Only patients in whom disabling fainting persisted despite the use of ephedrine were treated. In the first patient to be described there seems good evidence that the treatment was of specific value.

\section{CASE RePORTS}

Case 1. A 63-year-old file hardener was admitted to hospital in February 1960 with an acute myocardial infarction. An electrocardiogram showed sinus rhythm, an antero-septal infarct, and left bundle-branch block. He was treated with anticoagulants and general measures, and one week later the cardiogram showed extension of the infarct posteriorly. Six weeks later there was cardiographic evidence of improvement, sinus rhythm and left bundle-branch block persisting. He was treated as an out-patient and in December 1960 he complained of fainting attacks. Cardiograms showed a heart rate of 40 and 2:1 block. The syncopal attacks became increasingly frequent. He was unable to work or go out of doors and for 18 months lived confined to his room apart from visits to hospital by ambulance. In August 1962 he was admitted to the Cardiac Department for the first time as an emergency following a prolonged Adams-Stokes attack. He was stuporose with Cheyne-Stokes breathing. A cardiogram showed a heart rate of 25 with complete heart block (Fig. 1). In addition to general measures, prednisolone $10 \mathrm{mg}$. t.i.d. was given by injection. He recovered from his semi-comatose state and no further Adams-Stokes attacks occurred. On August 13 the heart rate was 40 and 2:1 block was present. The dose of prednisolone was reduced to $10 \mathrm{mg}$. twice daily and on August 20 a further reduction to $5 \mathrm{mg}$. twice daily was made. On August 27 he reverted to sinus rhythm with a heart rate of 80 and has remained in sinus rhythm since. He is now only slightly breathless on exertion and at the age of 65 is considering a return to work.

Case 2. A 75-year-old housewife first became aware of fainting attacks in 1955 . She was referred to hospital where complete heart block was found; she was treated with ephedrine, and after a few months had no further disability until 1959 when the attacks recurred. They persisted with increasing severity 


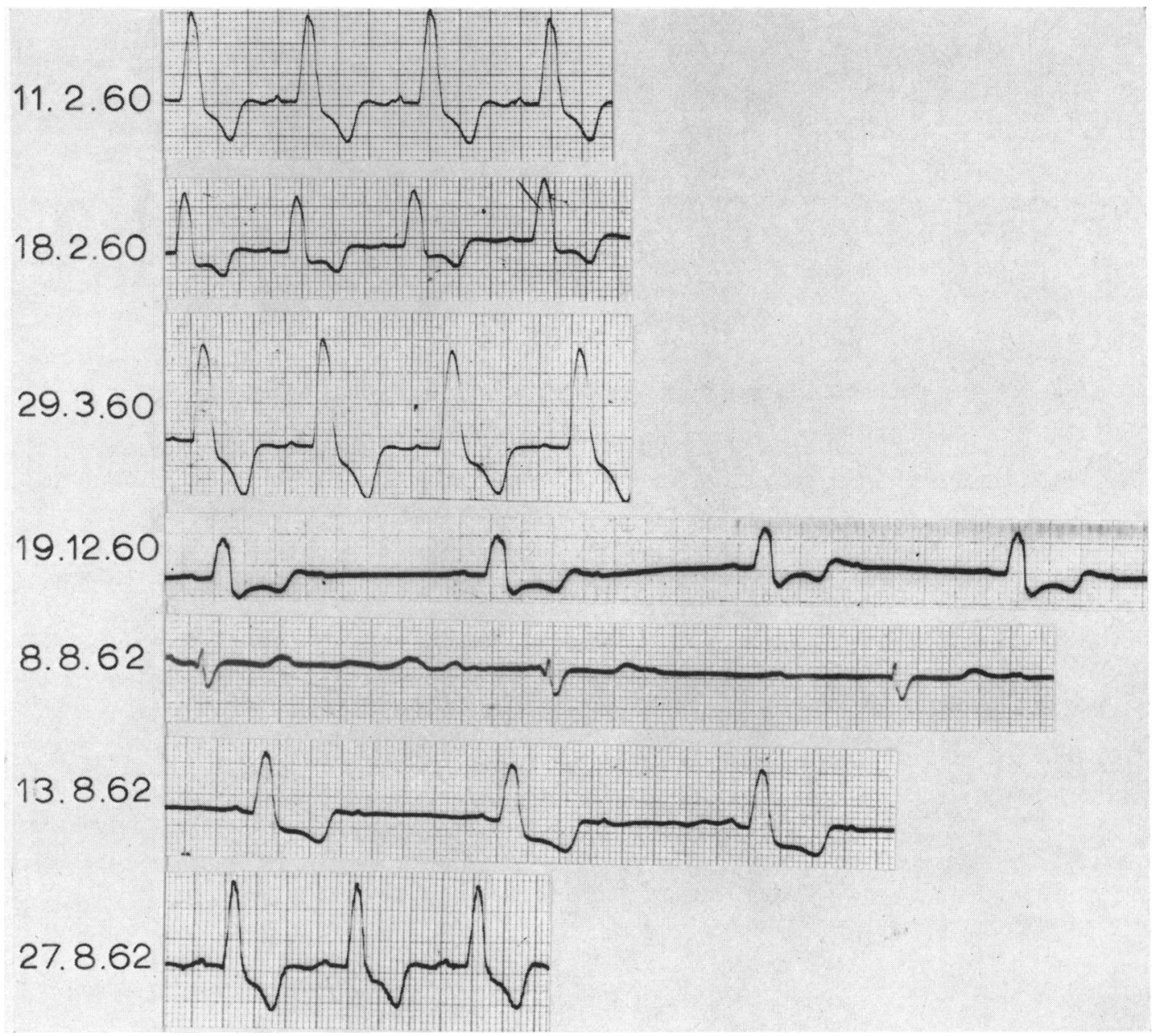

FIG. 1.-Electrocardiograms in Case 1. Standard lead I in all cases.

11.2.1960: sinus rhythm with left bundle-branch block.

18.2.1960: sinus rhythm with left bundle-branch block.

29.3.1960: sinus rhythm with left bundle-branch block.

19.12.1960: 2-1 heart block, rate 40.

8.8.1962: prednisone treatment started.

8.8.1962: complete heart block, rate 25 .

13.8.1962: 2-1 heart block, rate 40.

27.8.1962: sinus rhythm, rate 80 .

until 1961 when she was referred to the Cardiac Department. She was admitted in March when an electrocardiogram showed complete heart block and no evidence of myocardial infarction. She was treated with prednisone in addition to the ephedrine she had been receiving and the attacks ceased. During two years of observation in the out-patients' department she has had occasional mild attacks with no loss of consciousness, and for a short time the cardiogram showed sinus rhythm. She has taken prednisone $10 \mathrm{mg}$. daily with ephedrine $\frac{1}{2}$ gr. twice a day throughout this time and has, at the age of 82 , been getting about out of the house with confidence.

Case 3. A woman of 71 was first seen in April 1961. For two months it had been noted that her heart was slow and she had had frequent syncopal attacks. Ephedrine had been given without relief. The electrocardiogram showed complete heart block with evidence of ischæmic heart disease. Prednisone was 
given, and in December 1961 sinus rhythm with occasional ventricular ectopic beats was present. Treatment with prednisone was stopped and in March 1962 heart block was again found on the cardiogram. Ephedrine and prednisone were resumed and for the past nine months she has had only one syncopal attack, the cardiogram showing, during this period, varying degrees of block.

Case 4. A man, aged 49, was referred because of repeated Adams-Stokes attacks, and for six months they failed to respond to the usual measures: he had to give up work and remain indoors for fear of fainting. Treatment with prednisone had no apparent effect on the electrocardiogram but the Adams-Stokes attacks ceased. The most recent dose of prednisone was $2.5 \mathrm{mg}$. t.i.d. with ephedrine gr. $\frac{1}{2}$ t.i.d.

Case 5. An 80-year-old woman had complained of occasional syncopal attacks for several years, apparently alleviated somewhat by ephedrine. During the six months preceding her admission the attacks had become so frequent that she was confined to a chair. Prednisone $15 \mathrm{mg}$. t.i.d. was given with initially good results but although no further syncope occurred it became evident that advanced cerebral arteriosclerosis was making evaluation difficult.

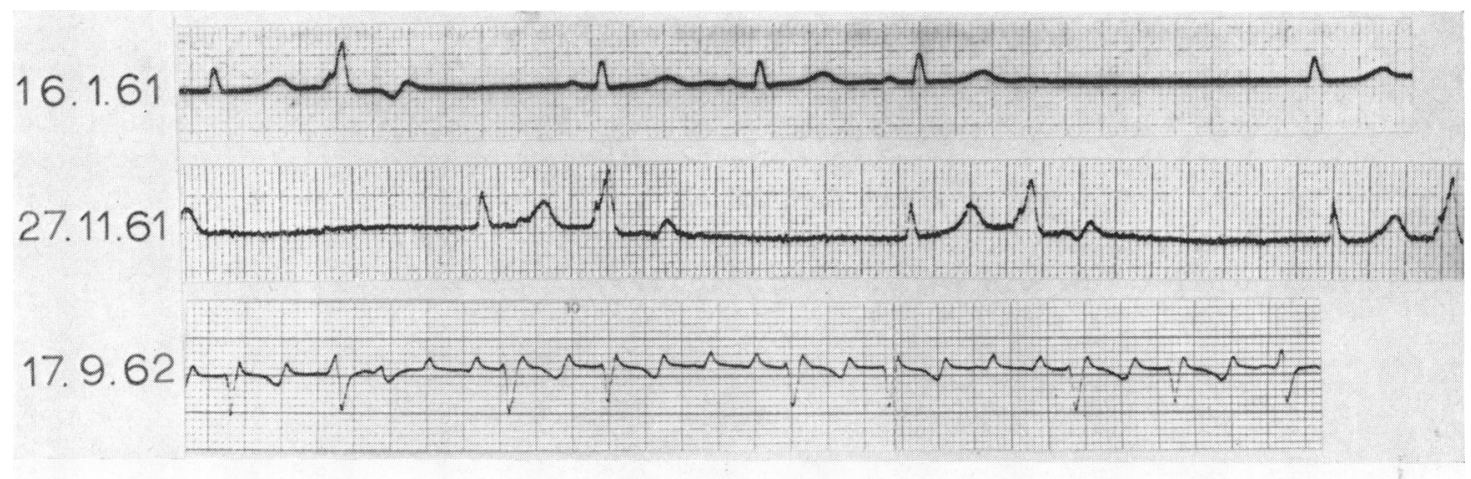

Fig. 2.-Electrocardiograms in Case 6.

16.1.1961: sinus rhythm with period of sinus arrest and nodal and ventricular extrasystoles (lead I).

27.11.1961: sinus rhythm (lead I).

17.9.1962: after treatment with prednisone. Atrial flutter with varying block.

Case 6. A 65-year-old man was referred to the out-patient department with a history of three years of dyspnœa and angina. He had had many dizzy attacks but had never fainted. Electrocardiograms showed sinus bradycardia with occasional ventricular ectopic beats, both nodal and ventricular in origin (Fig. 2). He was admitted to hospital where the bradycardia persisted despite intravenous injection of atropine and a trial of ephedrine. In June 1962 he reported having episodes in which he became unconscious and it was decided to try prednisone. This was given $5 \mathrm{mg}$. three times daily. During the succeeding six months he has remained fit with no symptoms. The cardiogram now shows atrial flutter with varying degrees of block.

Case 7. A man of 65 years complained for eight months of repeated syncopal attacks. Ephedrine had been given without effect and he had received no other therapy. Electrocardiography showed atrial fibrillation with much bradycardia. It was presumed that the attacks were Adams-Stokes in type and he was treated with prednisone. There was a rapid increase in the heart rate. The atrial fibrillation has persisted to date but there have been no further episodes of fainting.

\section{Discussion}

A number of authors have described benefit in Adams-Stokes attacks from steroid therapy. Following the account of Prinzmetal and Kennamer (1954), Rosenfeld and Segall (1955) mentioned two cases of heart block of whom one was relieved; Phelps and Lindsay (1957) abolished atrioventricular block with intramuscular prednisone; Tung, Lu, and Fu (1957) used corticotrophin in two cases and found Adams-Stokes attacks relieved in 24 hours; Perry and Jaeck (1960) gave oral 
cortisone to a patient with relief of syncope and reversion of complete heart block to $3: 1$ block: the patient relapsed and died when the therapy stopped. Litchfield, Manley, and Polak (1958) controlled attacks in three cases with corticotrophin. Aber and Wyn Jones (1960) found corticotrophin of value in five cases. Friedberg et al. (1960) reported six cases in which prednisone permanently or temporarily diminished or abolished heart block and relieved syncopal attacks: they reported that in some cases it was not possible to reduce the dose of prednisone to below $30 \mathrm{mg}$. daily. Torresani et al. (1962) report beneficial effects in seven cases.

The effects of treatment in a disease that is subject to remissions and relapses are notoriously difficult to assess. In the second case reported here a brief episode of syncope with heart block has occurred with apparently spontaneous recovery, and transient block in patients with acute infarction is not unknown. The results reported here must, therefore, be accepted with some caution. It seems probable, however, that in the first case reported, prednisolone was having a specific effect in reversing a slow deterioration which had been observed over two years. Similarly in the sixth case reported here, there had been a long period of observation before prednisone was prescribed, and the improvement in the patient's symptoms and change in the heart rate had occurred immediately. In the remaining cases the results are suggestive, but less conclusive. Experience in this series, however, is closely paralleled by that described by others and it seems likely that steroids may have a useful place in the therapy of Adams-Stokes attacks. The mechanism by which this good effect is produced is obscure. It is possible that the suggestion of Perry (1962) is correct and that the drug affects in a non-specific fashion the inflammatory damage to the conducting mechanism of the heart, but the effective dosage in several patients is so low that this seems unlikely.

\section{SUMMARY}

Prednisone was given to seven patients in whom Adams-Stokes attacks had failed to respond to ephedrine. A beneficial response appeared to follow, and in at least two patients the period of observation before the institution of this treatment makes it likely that the change was not spontaneous in origin but was a result of the administration of prednisone.

\section{REFERENCES}

Aber, C. P., and Wyn Jones, E. (1960). Complete heart block treated with corticotrophin and corticosteroid. Brit. Heart J., 22, 723.

Friedberg, C. K., Kahn, M., Scheuer, J., Bleifer, S., and Dack, S. (1960). Stokes-Adams syndrome associated with chronic heart block. Treatment with corticosteroids. J. Amer. med. Ass., 172, 1146.

Litchfield, J. W., Manley, K. A., and Polak, A. (1958). Stokes-Adams attacks treated with corticotrophin. Lancet, $1,935$.

Parkinson, J., Papp, C., and Evans, W. (1941). The electrocardiogram of the Stokes-Adams attack. Brit. Heart J., 3, 171 .

Perry, E. L. (1962). Corticosteroids in Stokes-Adams syndrome. Amer. Heart J., 64, 571.

, and Jaeck, J. L. (1960). Use of corticosteroids in Stokes-Adams syndrome. Ann. intern. Med., 53, 589.

Phelps, M. D., and Lindsay, J. D., Jr. (1957). Cortisone in Stokes-Adams disease secondary to myocardial infarction: report of a case. New Engl. J. Med., 256, 204.

Prinzmetal, M., and Kennamer, M. D. (1954). Emergency treatment of cardiac arrhythmias. J. Amer. med. Ass., 154, 1049 .

Rosenfeld, I., and Segall, H. N. (1955). An external cardiac pacemaker in the treatment of Stokes-Adams syndrome: Report of three cases. Amer. Heart J., 50, 749.

Torresani, J., Delaage, M., Jobin, A., and Jouve, A. (1962). Corticothérapie des blocs auriculo-ventriculaires. A propos de 7 observations. Arch. Mal. Caur, 55, 121.

Tung, C. L., Lu, S. T., and Fu, H. H. (1957). Corticophrine (ACTH) therapy of Morgagni-Adams-Stokes syndrome in patients with complete heart block. Chin. med.J., 75, 181.

\section{ADDENDUM}

Case 4. After nine months of freedom from Adams-Stokes attacks this man had a further episode of fainting. It was decided to try the effect of a long-lasting ephedrine compound. By this medication, he has again kept free of attacks for the past three months. 